\section{THE MICROBIAL TRANSFORMATION OF TYLOSIN \\ BY THE SPIRAMYCIN-PRODUCING STRAIN, STREPTOMYCES AMBOFACIENS KA-1028*}

Sir:

In previous papers ${ }^{1 \sim 4)}$, we have pointed out the usefulness of cerulenin ${ }^{5)}$, a specific inhibitor of fatty acid and polyketide biosyntheses, in examining the biosynthesis of 16 -membered macrolide antibiotics. Furthermore, the biosynthetic investigation suggested that the bioconversion using a microorganism which is a producer of an other macrolide antibiotic and in the presence of cerulenin seemed to be useful for producing new related macrolides. The present communication describes the microbial transformation of tylosin to a new compound by a spiramycin-producing strain, Streptomyces ambofaciens KA-1028, under conditions in which spiramycin biosynthesis is inhibited by cerulenin.

Strain KA-1028 was cultured in a 500-ml SAKAGUCHI flask containing $100 \mathrm{ml}$ of spiramycin production medium composed of $1.0 \%$ glucose, $1.0 \%$ dried yeast, $0.1 \% \mathrm{NaNO}_{3}, 0.5 \% \mathrm{NaCl}$ and $1.0 \% \mathrm{CaCO}_{3}$ (adjusted to $\mathrm{pH} 7.5$ with $2 \mathrm{~N} \mathrm{NaOH}$ prior to autoclaving). In order to inhibit production of the spiramycins, $40 \mu \mathrm{g} / \mathrm{ml}$ of cerulenin was added to the medium at the beginning and every 24-hour intervals. After 48-hour cultivation at $27^{\circ} \mathrm{C}, 100 \mu \mathrm{g} / \mathrm{ml}$ of tylosin was added to the culture, and the cultivation was continued for additional 24 hours. The cultured broth was centrifuged to remove mycelia and the supernatant was extracted with benzene. The benzene layer was concentrated to dryness in vacuo and the residue was purified by silica gel TLC (Kieselgel $60 \mathrm{~F}_{254}$, Merck) which was developed with $\mathrm{CHCl}_{3}$ $\mathrm{MeOH}-1.5 \mathrm{~N} \mathrm{NH}_{4} \mathrm{OH}$ (2:1:1, bottom layer) to give tylosin-related compounds. The microbial transformation of tylosin was monitored by a dual wavelength chromatogram scanner (Model CS-910, Shimadzu Seisakusho Co., Ltd.) scanned at $232 \mathrm{~nm}$ and $282 \mathrm{~nm}$. As shown in Fig. 1, two major peaks, $\mathrm{S}-1$ and $\mathrm{S}-2$, were detected on the chromatogram. Both compounds were isolated by means of preparative silica gel TLC which was developed with the same solvent system described above. The compound S-1 showed a UV absorption maximum at $282 \mathrm{~nm}$ indicating the presence of $\alpha, \beta, \gamma, \delta$-unsaturated ketone. It was identified as 20-dihydrotylosin (relomycin), one of the major components produced by the tylosin-producing strain of Streptomyces fradiae ${ }^{2}$, by comparison of silica gel TLC, IR and mass spectroscopies with those of authentic relomycin. The second compound, S-2, exhibited a UV ab-

Fig. 1. Bioconversion of tylosin by spiramycin-producing $S$. ambofaciens KA-1028.

Tylosin was added to the cerulenin-supplemented culture of KA-1028. After extraction with benzene, the bioconversion was examined by silica gel TLC which was scanned [A]: at $282 \mathrm{~nm}$, [B]: at 232 $\mathrm{nm}$.

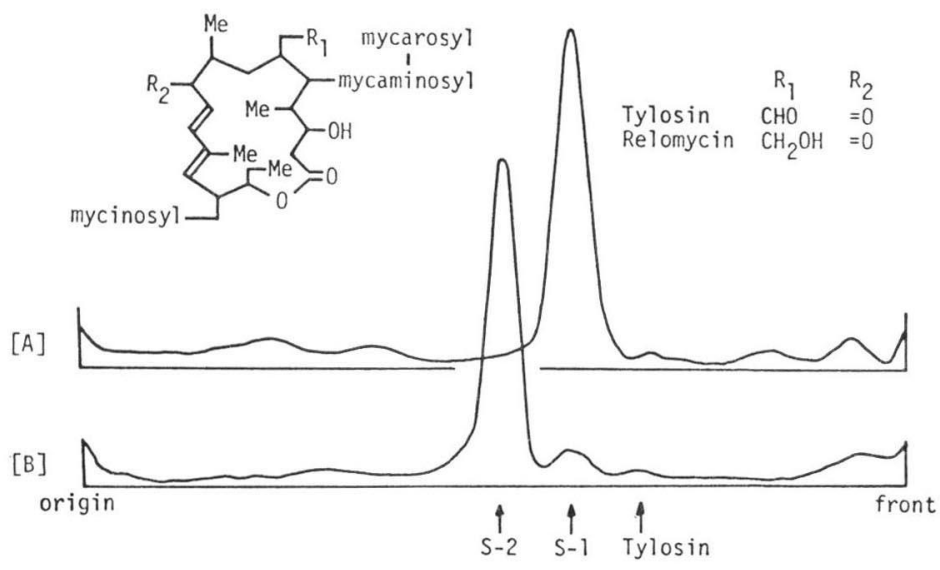

* Bioconversion and biosynthesis of 16-membered macrolide antibiotics. Part XVII. Part XVI of this series appears in: S. Ōmura, C. Kitao \& H. Matsubara, Chem. Pharm. Bull. 28: 1963 1965, 1980 
Fig. 2. Mass spectrum of 9,20-tetrahydrotylosin.

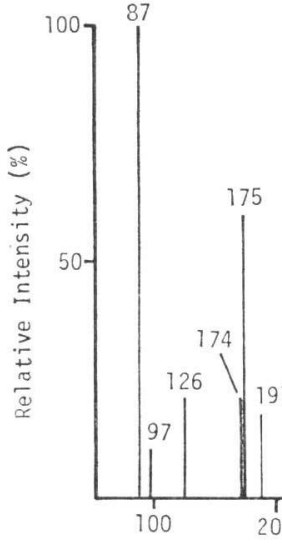

sorption maximum at $231.5 \mathrm{~nm}(\log \varepsilon=4.418$ in $\mathrm{MeOH}$ ), suggesting the presence of a conjugated diene corresponding to the leucomycin or spiramycin family of antibiotics. The infrared spectrum of compound S-2 showed a lack of bands at 2720 and $2820 \mathrm{~cm}^{-1}$, characteristic of the aldehyde group at the $\mathrm{C}-20$ position in tylosin. The compound S-2 was identified as 9,20-tetrahydrotylosin from the mass spectra; $m / e 919\left(\mathrm{M}^{+}\right), 901$ $\left(\mathrm{M}^{+}-\mathrm{H}_{2} \mathrm{O}\right), 775\left(\mathrm{M}^{+}\right.$- mycarosyl), $585\left(\mathrm{M}^{+}-\right.$ mycarosylmycaminosyl), 394 (aglycone), and 175 (mycinosyl) as shown in Fig. 2.

9, 20-Tetrahydrotylosin showed weak antimicrobial activity against Gram-positive bacteria (1/15 potency of tylosin in MIC against Sarcina lutea PCI 1001), but no activity against Gramnegative bacteria.

It is of interest that $S$. ambofaciens KA-1028 has no ability to reduce the aldehyde group of its own antibiotic, spiramycin, under the same condition described above.

\section{Acknowledgement}

The authors wish to thank Mr. T. SATO of this laboratory for his helpful technical assistances.

SATOSHI ŌMURA*

CHIAKI KITAO

NORIAKI SADAKANE
Kitasato University and The Kitasato Institute Minato-ku, Tokyo 108, Japan

(Received June 6, 1980)

\section{References}

1) Takeshima, H.; C. Kitao \& S. Ōmura: Inhibition of the biosynthesis of leucomycin, a macrolide antibiotic, by cerulenin. J. Biochem. 81: $1127 \sim 1132,1977$

2) Ömura, S.; C. Kitao, J. Miyazawa, H. Imai \& H. TAKESHIMA: Bioconversion and biosynthesis of 16-membered macrolide antibiotic, tylosin, using enzyme inhibitor, cerulenin. J. Antibiotics 31: 254 256, 1978

3) Ōmura, S.; C. Kitao, H. Hamada \& H. Ikeda: Bioconversion and biosynthesis of 16-membered macrolide antibiotics. X. Final steps in the biosynthesis of spiramycin, using enzyme inhibitor, cerulenin. Chem. Pharm. Bull. 27: 176 182, 1979

4) Kitao, C.; H. Hamada, H. Ikeda \& S. Ömura: Bioconversion and biosynthesis of 16-membered macrolide antibiotics. XV. Final steps in the biosynthesis of leucomycins. J. Antibiotics 32: $1055 \sim 1057,1979$

5) ÖMurA, S.: The antibiotic cerulenin, a novel tool for biochemistry as an inhibitor of fatty acid synthesis. Bact. Rev. 40: 681 697, 1976 